\title{
Preparation of Microcrystals of Piroxicam Monohydrate by Antisolvent Precipitation via Microfabricated Metallic Membranes with Ordered Pore Arrays
}

\author{
Rahimah Othman, ${ }^{* \dagger, \dagger}$ Goran T. Vladisavljević, ${ }^{* \dagger}{ }^{\dagger}$ Elena Simone, ${ }^{\dagger, \S}$ Zoltan K. Nagy, ${ }^{\dagger, \perp}$ \\ and Richard G. Holdich ${ }^{\dagger}$ \\ ${ }^{\dagger}$ Department of Chemical Engineering, Loughborough University, Ashby Road, Loughborough, Leicestershire LE11 3TU, U.K. \\ ${ }^{\ddagger}$ School of Bioprocess Engineering, Universiti Malaysia Perlis, Kompleks Pusat Pengajian Jejawi 3, 02600 Arau, Perlis, Malaysia \\ ${ }^{\S}$ School of Food Science and Nutrition, University of Leeds, Leeds, LS29JT, U.K. \\ ${ }^{\perp}$ School of Chemical Engineering, Purdue University, West Lafayette, Indiana 47907-2100, United States
}

\section{Supporting Information}

\begin{abstract}
Microcrystals of piroxicam (PRX) monohydrate with a narrow size distribution were prepared from acetone/ PRX solutions by antisolvent crystallization via metallic membranes with ordered pore arrays. Crystallization was achieved by controlled addition of the feed solution through the membrane pores into a well-stirred antisolvent. A complete transformation of an anhydrous form I into a monohydrate form of PRX was confirmed by Raman spectroscopy and differential scanning calorimetry. The size of the crystals was 7-34 $\mu \mathrm{m}$ and was controlled by the PRX concentration in the feed solution $\left(15-25 \mathrm{~g} \mathrm{~L}^{-1}\right)$, antisolvent/solvent volume ratio (5-30), and type of antisolvent (Milli-Q water or $0.1-0.5 \mathrm{wt}$

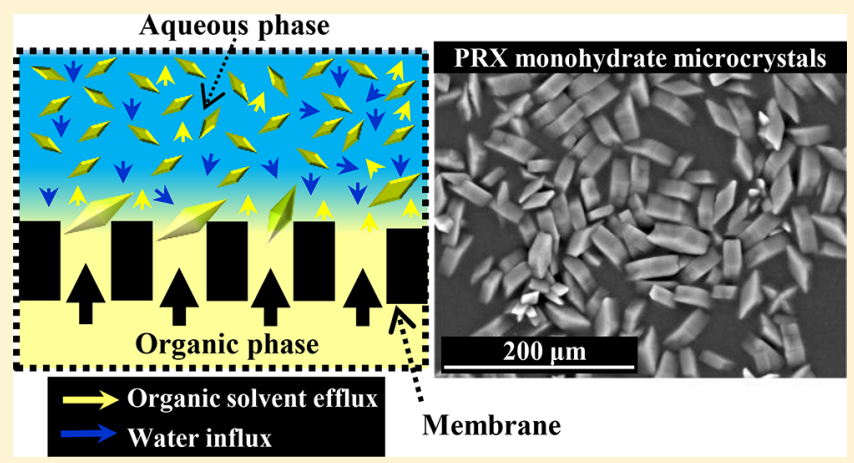
$\%$ aqueous solutions of hydroxypropyl methyl cellulose (HPMC), poly(vinyl alcohol) or Pluronic P-123). The smallest crystals were obtained by injecting $25 \mathrm{~g} \mathrm{~L}^{-1} \mathrm{PRX}$ solution through a stainless-steel membrane with a pore size of $10 \mu \mathrm{m}$ into a $0.06 \mathrm{wt} \%$ HPMC solution stirred at $1500 \mathrm{rpm}$ using an antisolvent/solvent ratio of 20. HPMC provided better steric stabilization of microcrystals against agglomeration than poly(vinyl alcohol) and Pluronic P-123, due to hydrogen bonding interactions with PRX and water. A continuous production of large PRX monohydrate microcrystals with a volume-weighted mean diameter above $75 \mu \mathrm{m}$ was achieved in a continuous stirred membrane crystallizer. Rapid pouring of Milli-Q water into the feed solution resulted in a mixture of highly polydispersed prism-shaped and needle-shaped crystals.
\end{abstract}

\section{INTRODUCTION}

Low aqueous solubility of active pharmaceutical ingredients (APIs) is a major problem in the design of pharmaceutical dosage forms. ${ }^{1-3}$ Over $60 \%$ of APIs fall under BCS Class II (low solubility and high permeability) or Class IV (low solubility and low permeability). As such, they suffer from low bioavailability and incomplete/erratic adsorption. ${ }^{4,5}$ A low drug solubility leads to a low concentration gradient in the liquid medium, resulting in a low dissolution rate of the drug, according to the Noyes-Whitney equation. Drug bioavailability can be improved by increasing the surface area of a drug substance, which depends on its particle size. ${ }^{2,6}$

The surface area of drug substances can be increased by mechanical milling, ${ }^{7}$ high pressure homogenization, ${ }^{8}$ and spray drying. ${ }^{9}$ However, these techniques require high energy inputs and expensive equipment, and often lead to a broad particle size distribution, thermal degradation, heterogeneous particle shapes, and poor batch-to-batch reproducibility. ${ }^{3,4,10}$ Anti- solvent precipitation/crystallization is an alternative approach to prepare fine drug particles. ${ }^{11,12}$ The technique is simple and does not require elevated temperatures, high energy inputs, and Class 1 solvents. ${ }^{13-17}$ It has been used to prepare ultrafine powders and micro-/nanodispersions of many APIs, including budesonide, ${ }^{18}$ danazol, ${ }^{19}$ beclomethasone dipropionate, ${ }^{20}$ griseofulvin and fenofibrate, ${ }^{21}$ salbutamol sulfate, ${ }^{22}$ prednisolone, ${ }^{23}$ atorvastatin, ${ }^{24}$ L-glutamic acid, ${ }^{25}$ and paracetamol. ${ }^{26}$

Piroxicam (PRX, 4-hydroxy-2-methyl- $\mathrm{N}$-(2-pyridyl)-2H-1,2benzothiazine-3-carboxamide-1,1-dioxide) is a nonsteroidal anti-inflammatory drug, which is mainly used in the treatment of rheumatic diseases. ${ }^{27}$ PRX is a BCS Class II drug with a high intestinal membrane permeability, but low water solubility. ${ }^{28}$ PRX has three anhydrous white polymorphs, forms I, II, and

Received: September 14, 2017

Revised: November 9, 2017

Published: November 13, 2017 


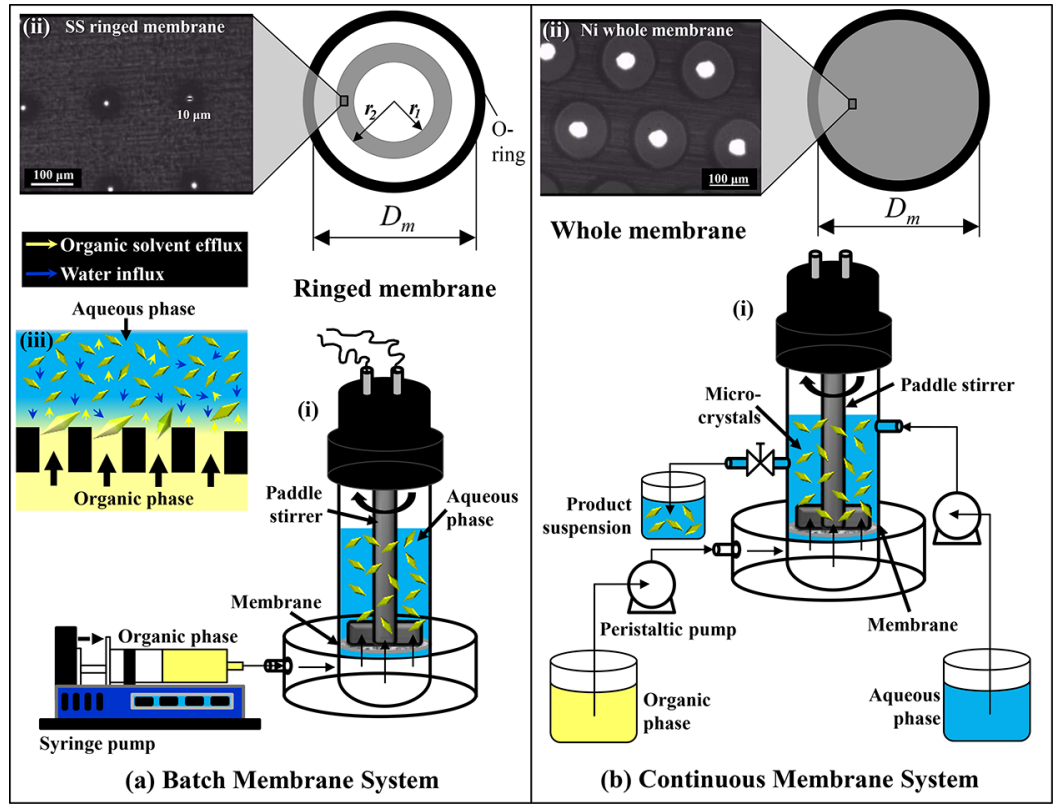

Figure 1. (a) Batch membrane dispersion system consisting of (i) stirred cell and (ii) ringed stainless-steel (SS) membrane with 10- $\mu \mathrm{m}$ laser drilled pores $\left(D_{\mathrm{m}}=3.3 \mathrm{~cm}, r_{1}=0.9 \mathrm{~cm}, r_{2}=1.3 \mathrm{~cm}\right)$; (b) continuous membrane dispersion system composed of (i) continuous flow stirred cell and (ii) nickel membrane with $40-\mu \mathrm{m}$ pores $\left(D_{\mathrm{m}}=3.3 \mathrm{~cm}\right)$. Microcrystals were formed in the cell above the membrane surface, as shown in inset panel a (iii).

III, whose crystal structure was confirmed ${ }^{29}$ and one yellow monohydrate form. Anhydrous forms contain neutral PRX molecules in their crystal lattices, whereas the monohydrate form contains zwitterionic piroxicam molecules. The monohydrate form converts to anhydrous forms by heating at high temperatures, while the anhydrous forms revert to the monohydrate form in aqueous solutions. Since different polymorphs of PRX display different pharmacokinetic and pharmacodynamic properties, ${ }^{30}$ a crystallization process must be carried out in such a way to gain control over the polymorphic form of PRX obtained.

Coupling membrane permeation with antisolvent crystallization is a promising strategy to precisely control the level of supersaturation owing to controllable mass transfer rates across the membrane. ${ }^{31-33}$ The most common approach is to combine membrane distillation with antisolvent crystallization. ${ }^{34,35}$ In this approach, the membrane is hydrophobic and the transmembrane pressure difference is sufficiently small such that the liquid cannot penetrate the pores, so that the transfer of solvent and antisolvent between the two contacting liquids is carried out in vapor phase across the air-filled pores. Since the temperature and/or concentration difference must be maintained across the membrane to create a vapor pressure gradient, the process is complicated, slow, and associated with relatively high energy consumption.

An alternative approach suggested by Bakker et al. ${ }^{36}$ is to force a crystallizing solution through the membrane directly into the antisolvent by overcoming the capillary pressure in the pores. In this process, the wetting properties of the membrane are not critically important, except for the fact that hydrophilic membranes can achieve higher fluxes of aqueous solutions. ${ }^{35}$ By using the membrane as a precision dosing device, efficient micromixing of the feed solution and the antisolvent can be achieved. The membrane pores act as numerous micron-sized feed introduction points, which results in uniform supersaturation along the membrane. Compared to evaporative membrane crystallization, the process is much faster and less energy demanding, since it does not require any heat transfer. Fine tuning of the mixing process can be achieved by proper membrane selection and adjusting the level of shear stress on the membrane surface by controlled cross-flow, ${ }^{37}$ stirring, ${ }^{16}$ pulsed cross-flow, ${ }^{38}$ and low frequency membrane vibration ${ }^{39}$ or rotation. ${ }^{40}$

In this work, microcrystals of PRX monohydrate have been prepared for the first time using antisolvent membrane crystallization process. The feed solution was dispersed into antisolvent using two different microengineered membranes, stainless steel membrane with laser drilled pores and electroformed nickel membrane. Metallic membranes with evenly spaced uniform pores have extensively been used for dispersion. ${ }^{16,41-43}$ Because of their isoporous structure, small thickness, and straight and nontortuous pores, they offer uniform micromixing, low resistance to flow, and suppression of internal fouling. The effect of pore morphology and spatial arrangement of the pores on the rate of micromixing was investigated elsewhere. ${ }^{17}$ The main objective of this work was to elucidate the effects of formulation factors, operating conditions, and mode of system operation on the morphology, polymorphic form, and size distribution of the produced PRX microcrystals.

\section{MATERIALS AND METHODS}

2.1. Chemicals. Piroxicam (PRX) (99\% purity, anhydrous) was obtained from Hangzhou Hyper Chemicals Limited (Zhejiang, China). Acetone (purity $\geq 99.98 \%$ ) supplied from Fisher Scientific, UK was used as a solvent for PRX. Poly(vinyl alcohol) (PVA, $M_{\mathrm{w}}=$ 13000-23000 $\mathrm{g} \mathrm{mol}^{-1}, 87-89 \%$ hydrolyzed), a symmetric triblock copolymer Pluronic P-123 $\left(M_{\mathrm{n}} \approx 5800\right)$, and hydroxylpropyl methylcellulose (HPMC, $M_{\mathrm{w}} \approx 10,000$ ) were purchased from Sigma-Aldrich, UK, and used as surfactants. The antisolvent was Milli- $Q$ water or aqueous surfactant solutions. The feed solution was a PRX/acetone mixture containing $15-25 \mathrm{~g} \mathrm{~L}^{-1}$ of PRX. At the lower PRX concentration $(<15 \mathrm{~g} / \mathrm{L})$, the solution could not easily nucleate, 
(a)

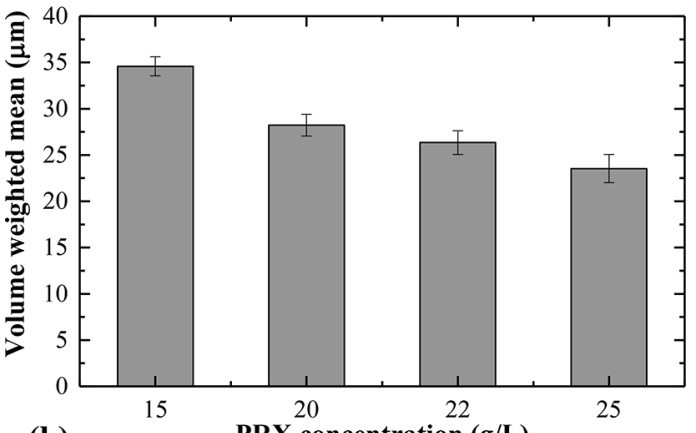

(b)

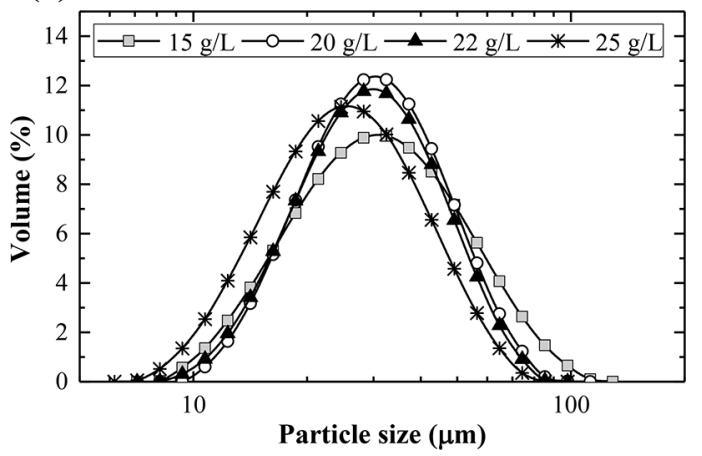

(c)

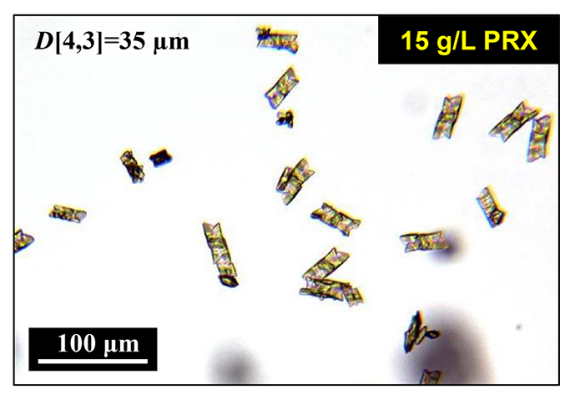

(d)

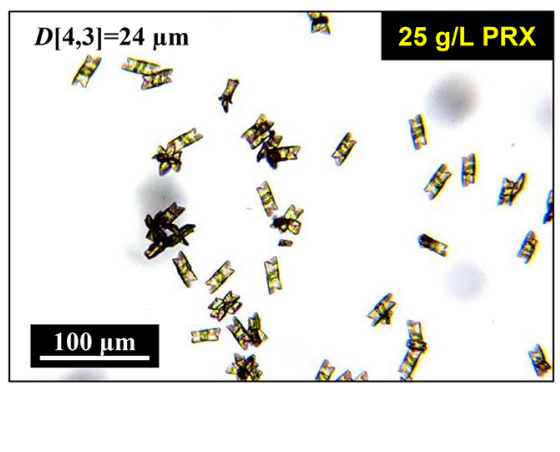

Figure 2. Effect of content of PRX in the feed solution on (a) the mean diameter; and (b) the size distribution of the microcrystals. The optical micrographs of PRX microcrystals produced at the PRX content of (c) $15 \mathrm{~g} \mathrm{~L}^{-1}$; (d) $25 \mathrm{~g} \mathrm{~L}^{-1} . V_{\mathrm{aq}} / V_{\mathrm{or}}=10$, ringed stainless-steel membrane, no surfactant was added.

and the maximum solubility of PRX in acetone at the room temperature was about $25 \mathrm{~g} / \mathrm{L}$.

2.2. Dispersion Cell. The experiments in Sections 3.1-3.6 were carried out using a batch membrane system (Figure 1a) consisting of a stirred cell and a ringed stainless-steel (SS) membrane, both supplied by Micropore Technologies Ltd. (Redcar, UK). The stirring blade was fixed in the cell $2.4 \mathrm{~cm}$ above the membrane surface. The SS membrane had about 6900 cylindrical pores with a diameter of $10 \mu \mathrm{m}$ fabricated by laser ablation. The pores were arranged in a square lattice, $200 \mu \mathrm{m}$ spaced apart, and occupied a circular ring region on the membrane surface with an area of $A_{\mathrm{r}}=2.76 \mathrm{~cm}^{2}$ (Figure $1 \mathrm{a}(\mathrm{ii})$ ). A nickel membrane with an effective cross-sectional surface area of $A=$ $8.55 \mathrm{~cm}^{2}$ was used in a continuous system shown in Figure $1 \mathrm{~b}$. The nickel membrane consisted of $\sim 24690$ pores with a diameter of $40 \mu \mathrm{m}$ fabricated by electroforming. The pores were arranged over the whole membrane surface in a hexagonal lattice and spaced apart at the distance of $200 \mu \mathrm{m}$ (Figure $1 \mathrm{~b}(\mathrm{ii})$ ). The whole membrane was less prone to fouling in continuous operation, because it was operated at the smaller flux than the ringed membrane.

2.3. Experimental Setup. 2.3.1. Batch System. The cell was filled with $15-90 \mathrm{~mL}$ of the antisolvent. The stirrer speed was adjusted at $1,500 \mathrm{rpm}$, which generated a peak shear stress of $17.5 \mathrm{~Pa}$ at the radial distance of $r=1.1 \mathrm{~cm}$ from the center of the membrane. The feed solution ( $3 \mathrm{~mL}$ of $15-25 \mathrm{~g} \mathrm{~L}^{-1}$ PRX in acetone) was injected through the membrane at the flow rate of $Q=18 \mathrm{~mL} \mathrm{~min}{ }^{-1}$ using a syringe pump (11 Elite, Harvard Apparatus, UK). The final antisolvent/ solvent volume ratio was 5-30, depending on the volume of the antisolvent used. The flux through the ringed membrane, $J_{\mathrm{r}}=Q_{\mathrm{or}} / A_{\mathrm{r}}$, was $4,000 \mathrm{~L} \mathrm{~m}^{-2} \mathrm{~h}^{-1}$. The antisolvent turned to a bumblebee yellow color due to solvent-antisolvent displacement, resulting in the creation of supersaturation that was relieved by crystal nucleation and growth (Figure 1a (iii)). After organic phase injection, the suspension of microcrystals was stirred in the cell for additional $2 \mathrm{~min}$ and acetone was then allowed to completely evaporate. Each experiment was repeated three times. No significant difference in CSD was detected before and after solvent evaporation, as described in Figure S1 (Supporting Information).
2.3.2. Continuous System. This system shown in Figure $2 \mathrm{~b}$ was provided by Micropore Technologies Ltd. (Redcar, UK). The feed solution with $15 \mathrm{~g} \mathrm{~L}^{-1} \mathrm{PRX}$ was continuously injected through the membrane at $18 \mathrm{~mL} \mathrm{~min}{ }^{-1}$ using a peristaltic pump (Masterflex L/S 7544-06 drive, Cole-Parmer, IL). Milli-Q water was continuously supplied to the cell chamber at $90 \mathrm{~mL} \mathrm{~min}^{-1}$ using a Watson Marlow $503 \mathrm{U}$ peristaltic pump and stirred at $1500 \mathrm{rpm}$. Therefore, the flow rate ratio, $Q_{\mathrm{aq}} / Q_{\mathrm{or}}$ was 5 and the flux through the membrane, $J=Q_{\mathrm{or}} /$ $A$, was $1260 \mathrm{~L} \mathrm{~m}^{-2} \mathrm{~h}^{-1}$. The product suspension was discharged from the cell by hydrostatic head difference between the liquid level in the cell and the end of the outlet hose. The liquid level was regulated with a pinch valve installed in the outlet hose, which ensured a constant liquid volume in the cell of $100 \mathrm{~mL}$. The samples of the product stream were collected regularly over $15 \mathrm{~min}$ and analyzed.

The used membrane was cleaned by sonication in acetone for 30 min, according to the procedure described elsewhere. ${ }^{16}$

2.4. Characterization Techniques. 2.4.1. Particle Size Distribution. The crystal size distribution (CSD) was measured by laser diffraction using a Malvern Mastersizer 2000 (Worcestershire, UK). A saturated aqueous solution of piroxicam monohydrate was used as a dispersant. The relative volume, $V_{i}$, of the particles in different size classes $i$, whose mean diameter $d_{i}$ ranged from 0.01 to $3500 \mu \mathrm{m}$, was used to calculate the volume-weighted mean diameter, $d[4,3]$ :

$$
d[4,3]=\frac{\sum V_{i} d_{i}}{\sum V_{i}}
$$

The size uniformity of the crystals was estimated using span of a CSD: ${ }^{44}$

$$
\operatorname{span}=\frac{[d(v, 0.9)-d(v, 0.1)]}{d(v, 0.5)}
$$

where $d(v, 0.1), d(v, 0.5)$, and $d(v, 0.9)$ are the particle diameters at $10 \mathrm{vol} \%, 50 \mathrm{vol} \%$, and $90 \mathrm{vol} \%$ of the cumulative distribution.

2.4.2. Raman Microscopy. The polymorphic form of PRX crystals was determined using a Thermo Scientific DXR Raman microscope with a $780 \mathrm{~nm}$ laser. Each spectrum was acquired using a $10 \times$ 
Olympus objective lens by averaging 10 scans, collected within $10 \mathrm{~s}$ each.

2.4.3. Differential Scanning Calorimetry (DSC) and Scanning Electron Microscopy (SEM). DSC was carried out using a TA 2910 instrument to validate the results obtained by Raman spectroscopy. The crystals were isolated from the mother liquor by centrifuging and freeze-drying (Edwards, type EF4Modulyo freeze-dryer). A 5-10 mg of the sample (freeze-dried crystals or raw PRX) was weighed into an aluminum pan, then hermetically sealed and heated to $350^{\circ} \mathrm{C}$ at a scan rate of $10{ }^{\circ} \mathrm{C} \mathrm{min}^{-1}$. A second empty pan was used as a reference. A purge gas was dry nitrogen at $60 \mathrm{~mL} \mathrm{~min}{ }^{-1}$. Each measurement was repeated three times. SEM three-dimensional (3D) images of PRX microcrystals were acquired using a Hitachi model TM3030 benchtop SEM according to the procedure described by Othman at al. ${ }^{16}$

\section{RESULTS AND DISCUSSION}

3.1. Effect of the PRX Concentration in the Feed Solution. The effect of PRX concentration in the feed solution on the average size of the microcrystals is shown in Figure 2a. The $d[4,3]$ value decreased with an increase in PRX concentration from $35 \pm 1.0 \mu \mathrm{m}$ at $15 \mathrm{~g} \mathrm{~L}^{-1}$ to $24 \pm 1.5 \mu \mathrm{m}$ at $25 \mathrm{~g} \mathrm{~L}^{-1}$.

In the absence of attrition and agglomeration, the mean crystal size depends on the interplay between nucleation and growth. The rate of crystal growth is $G=K_{\mathrm{g}}\left(C_{\mathrm{PRX}}-C_{\mathrm{PRX}}{ }^{*}\right)^{g}$, where $K_{\mathrm{g}}$ is the growth constant, $C_{\mathrm{PRX}}$ and $C_{\mathrm{PRX}}{ }^{*}$ are the bulk concentration and solubility of PRX, respectively, and $g$ is $1-2$ for organic solutes. The rate of primary nucleation is $B=$ $K_{b}\left(C_{\mathrm{PRX}}-C_{\mathrm{PRX}}{ }^{*}\right)^{b}$, where $K_{b}$ is the nucleation constant, and $b$ is 5-10. The promotion of crystal growth over nucleation leads to fewer and larger crystals. Since $b \gg g$, crystal growth is favored at lower supersaturations and vice versa. ${ }^{19,45,46}$ Lower supersaturation was achieved using lower concentration of PRX in the feed solution. However, the rate of nucleation does not depend only on the degree of supersaturation, but also on the concentration of crystals in the cell, i.e., crystal-crystal collisions, which can promote secondary nucleation ("contact secondary nucleation”).

The CSD data shown in Figure $2 b$ are consistent with the above discussion. The minimum crystal size was achieved at 25 $\mathrm{g} \mathrm{L}^{-1}$ PRX, due to higher supersaturation and higher concentration of crystals in suspension, resulting in more pronounced primary and secondary nucleation. The similar behavior was reported in conventional antisolvent crystallization of drugs such as roxithromycin, ${ }^{47}$ megestrol acetate, ${ }^{48}$ and beclomethasone dipropionate. ${ }^{20}$

The CSD data are confirmed by optical microscopy (Figure $2 \mathrm{c}-\mathrm{d}$ ) with the larger crystals obtained at the smaller PRX concentration. However, crystal aggregation was more pronounced at the higher PRX concentration in the feed solution, due to the higher concentration of crystals in suspension and the absence of surfactant in the aqueous phase.

3.2. Effect of Stabilizer. In this section, aqueous solutions of PVA, P-123, and HPMC of different concentrations were used as the antisolvent phase. The PRX content in the feed solution was $25 \mathrm{~g} \mathrm{~L}^{-1}$ and the antisolvent/solvent volume ratio was 10 . The effect of surfactant concentration on $d[4,3]$ for three different surfactants is shown in Figure 3a. When pure water was used as the antisolvent, $d[4,3]$ was $24.0 \pm 1.5 \mu \mathrm{m}$.

Crystallization kinetics and crystal habit can be greatly influenced by the adsorption of surfactants onto crystalline faces. At very low concentrations, surfactants have the ability to decrease the interfacial tension at a crystal phase/liquid interface, $\gamma_{S L}$, thus lowering the height of the free energy

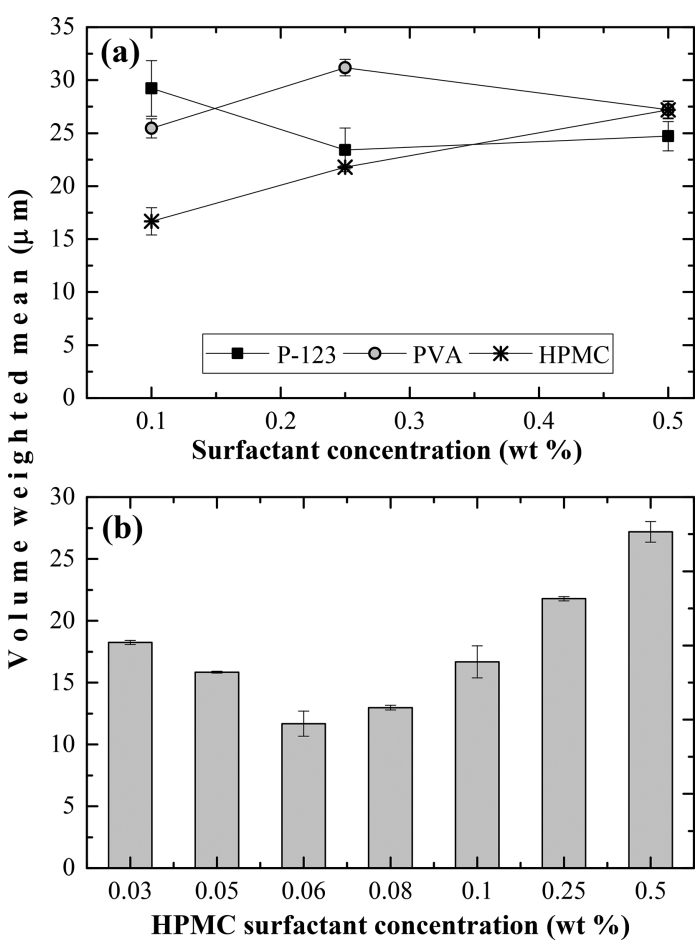

Figure 3. Effect of surfactant concentration in the aqueous phase on the volume-weighted mean diameter of the microcrystals for (a) P123 , PVA, and HPMC at $0.1,0.25$, and 0.5 wt \%; (b) HPMC at $0.03-$ $0.5 \mathrm{wt} \%$. The concentration of PRX in the organic phase $=25 \mathrm{~g} \mathrm{~L}^{-1}$, $V_{\text {aq }} / V_{\text {or }}=10$, ringed SS membrane.

barrier for nucleation, which is given by $\Delta G^{*}=16 \pi \gamma_{\mathrm{SL}}{ }^{3} v^{2} / 3(k T$ $\ln S)^{2}$, where $v$ is the volume of a solute molecule in the crystal, $k$ is the Boltzmann's constant, $T$ is the absolute temperature, and $S$ is the supersaturation ratio. Therefore, $\Delta G^{*}$ is proportional to the third power of $\gamma_{\mathrm{SL}}$, and any decrease in $\gamma_{\mathrm{SL}}$ will strongly reduce $\Delta G^{*}$ and increase the rate of nucleation. However, above the surfactant critical micelle concentration (CMC), $\gamma_{S L}$ is no longer affected by the surfactant concentration, but nuclei of hydrophobic drugs can be solubilized inside hydrophobic micellar cores, which can inhibit their growth. Also, surfactants can inhibit the rate of mass transfer across the interface by increasing the solution viscosity or interacting with solute molecules in the solution, e.g., through hydrogen bonding. Surfactant molecules can also selectively adsorb onto one or more crystal faces and retard the growth of the crystal in that direction, thus affecting the final crystal shape. ${ }^{49-51}$ Finally, surfactants can prevent agglomeration of small crystallites into large secondary assemblies by providing steric hindrance. ${ }^{52}$ Because of complexity and multiplicity of possible effects, no generalization can be made as to the effect of surfactants on the nucleation and growth kinetics of an arbitrary system.

The $d[4,3]$ values for PVA and P-123 in Figure 3a have inconclusive trends, revealing a complex interplay of different mechanisms of nucleation inhibition/promotion in the presence of these surfactants. Over the concentration range of $0.1-0.5$ wt $\%$, the smallest $d[4,3]$ value of $18 \mu \mathrm{m}$ was achieved with $0.1 \mathrm{wt} \%$ HPMC. To find the optimum HPMC concentration, additional experiments have been carried out in the range of $0.03-0.1 \mathrm{wt} \%$, as shown in Figure $3 \mathrm{~b}$. The smallest crystals with a $d[4,3]$ value of $13 \mu \mathrm{m}$ were achieved at 0.06 wt \% HPMC. A decrease in $d[4,3]$ on increasing the 


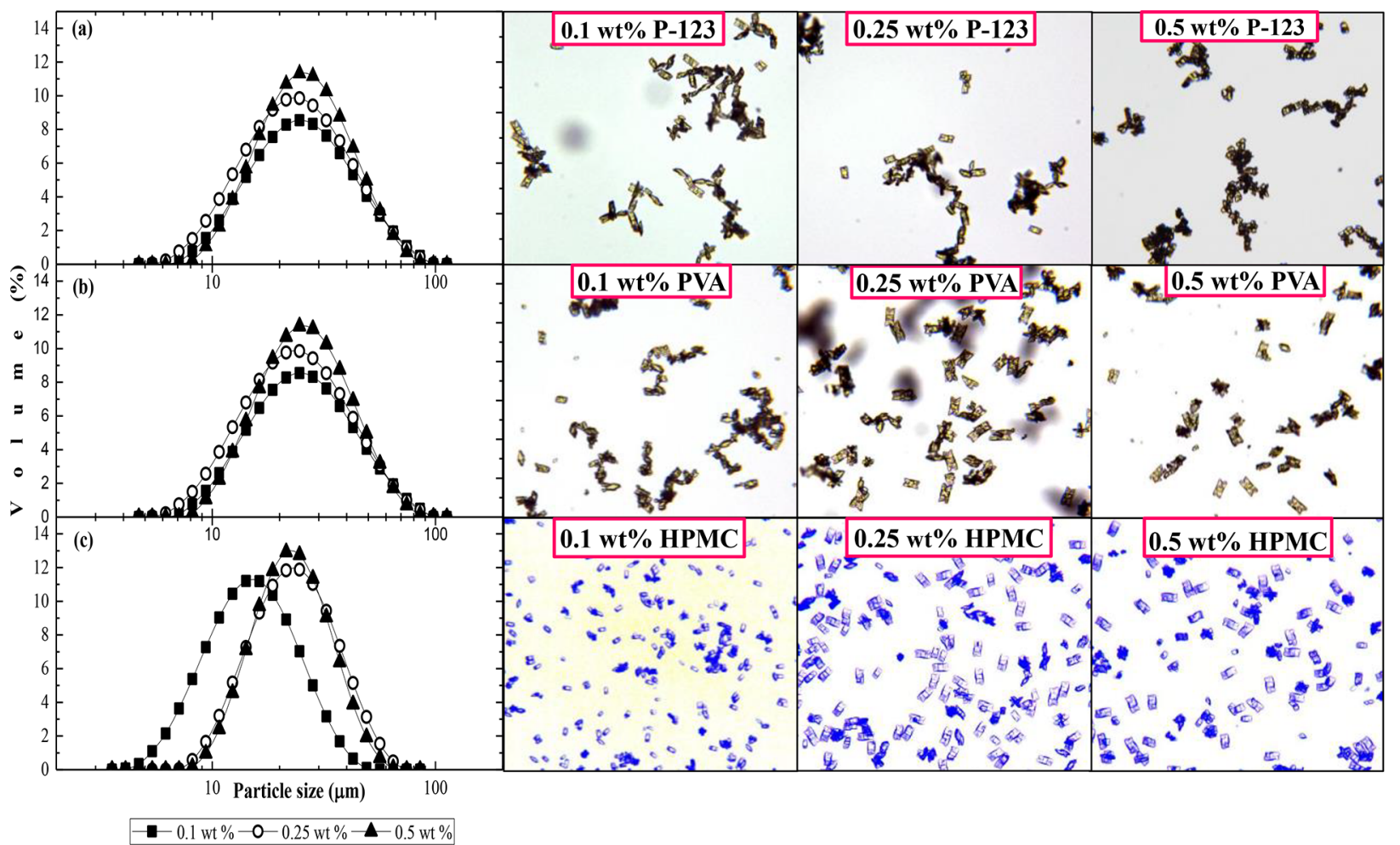

Figure 4. Size distribution and optical micrographs of the microcrystals stabilized with different surfactants: (a) $0.1-0.5$ wt $\%$ P-123; (b) $0.1-0.5$ wt $\%$ PVA; and (c) $0.1-0.5$ wt \% HPMC. The concentration of PRX in organic phase $=25 \mathrm{~g} \mathrm{~L}^{-1}, V_{\mathrm{aq}} / V_{\mathrm{or}}=10$, ringed SS membrane.

HPMC concentration from 0.03 to 0.06 wt \% can be explained by lowering the thermodynamic barrier for nucleation, due to a decrease in $\gamma_{S L}{ }^{53}$ which increases the nucleation rate, ultimately resulting in smaller crystals. The maximum in the nucleation rate occurs close to the CMC of HPMC. Once the maximum degree of adsorption has been reached, further addition of HPMC will result in the formation of micelles in solution, without any significant change in $\gamma_{S L}$. An increase in $d[4,3]$ from 0.03 wt $\%$ to $0.5 \mathrm{wt} \%$ HPMC was due to increased solution viscosity and hydrogen bonding interactions between HPMC and water or drug molecules. The viscosity of $0.5 \mathrm{wt} \%$ HPMC solution is 2.3 times higher than the viscosity of pure water. ${ }^{54}$ The nucleation rate is directly proportional to the jump frequency of growth units, $\Gamma$, from one site to another: $\Gamma$ $=k T /\left(3 \pi \lambda^{3} \eta\right)$, where $\lambda$ is the diameter of the growth units. Therefore, $\Gamma$ is inversely proportional to the viscosity of the solution, $\eta$. A higher solution viscosity also leads to a higher rate of solvent interdiffusion, ${ }^{55}$ which can have a strong impact on the supersaturation generated. Typically, lower rates of counter-diffusion of solvent and antisolvent lead to lower supersaturations.

At higher concentrations, HPMC strongly inhibits the formation of PRX monohydrate nuclei. It can be explained by HPMC molecules forming hydrogen bonds with water, which can immobilize water molecules and hinder their incorporation into the crystal lattice. ${ }^{26,56,57}$ Similar behavior was observed by Tian et al., ${ }^{58}$ who found that the phase transformation of anhydrous carbamazepine polymorphic forms I and III to the dihydrate was inhibited in aqueous HPMC solutions. In addition, HPMC can form hydrogen bonds with $\mathrm{PRX}$ via $\mathrm{OH}$ groups in HPMC and PRX molecules.

Figure 4 shows the size distribution curves and optical micrographs of the microcrystals stabilized by P-123, PVA, and
HPMC, for three different surfactant concentrations $(0.1,0.25$, and $0.5 \mathrm{wt} \%)$. From the micrographs, the smallest microcrystals were produced with 0.1 wt \% HPMC, which agrees with the results shown in Figure 3a.

The most uniform crystals were obtained for the highest concentration of each surfactant. The most severe agglomeration was observed with P-123 (Figure 4a). Agglomeration occurs when two or more crystals in the suspension collide and stay in contact long enough for the growth of an agglomerative bond. The variations in the structure of the adsorbed surfactant layer and steric hindrance effects lead to considerable differences in the forces required for the crystal faces to come into contact, as well as in the growth rate of the agglomerative bond and its subsequent strength. ${ }^{59}$ The highest stability against agglomeration was observed for HPMC (Figure 4c), due to high steric stabilization exerted by this surfactant. HPMC was observed to reduce sticking of cefuroxime axetil crystals to stirrer blades due to its high affinity toward newly formed crystal surfaces. ${ }^{60}$ The optimal HPMC concentration for stabilizing microcrystals of cefuroxime axetil was found to be $0.1 \%(\mathrm{w} / \mathrm{v}),{ }^{60}$ while in this study the optimal HPMC concentration for stabilizing microcrystals of PRX monohydrate was $0.06 \mathrm{wt} \%$. The adsorption of surfactants can be surfacespecific or nonspecific. In the case of surface-specific adsorption of surfactants onto the crystal surface, the surfactant molecules will selectively adsorb onto a crystal face and retard the growth of the crystal in that direction, thereby changing the crystal shape. ${ }^{61}$ In this study, prism-shaped microcrystals were obtained in the presence of all surfactants, as well as in Milli$\mathrm{Q}$ water, meaning that all surfactants adsorbed on all faces unselectively. Typically, low molecular weight surfactants adsorb on specific crystal surfaces, whereas surfactants with larger molecules, like those used in this study, are nonspecific 


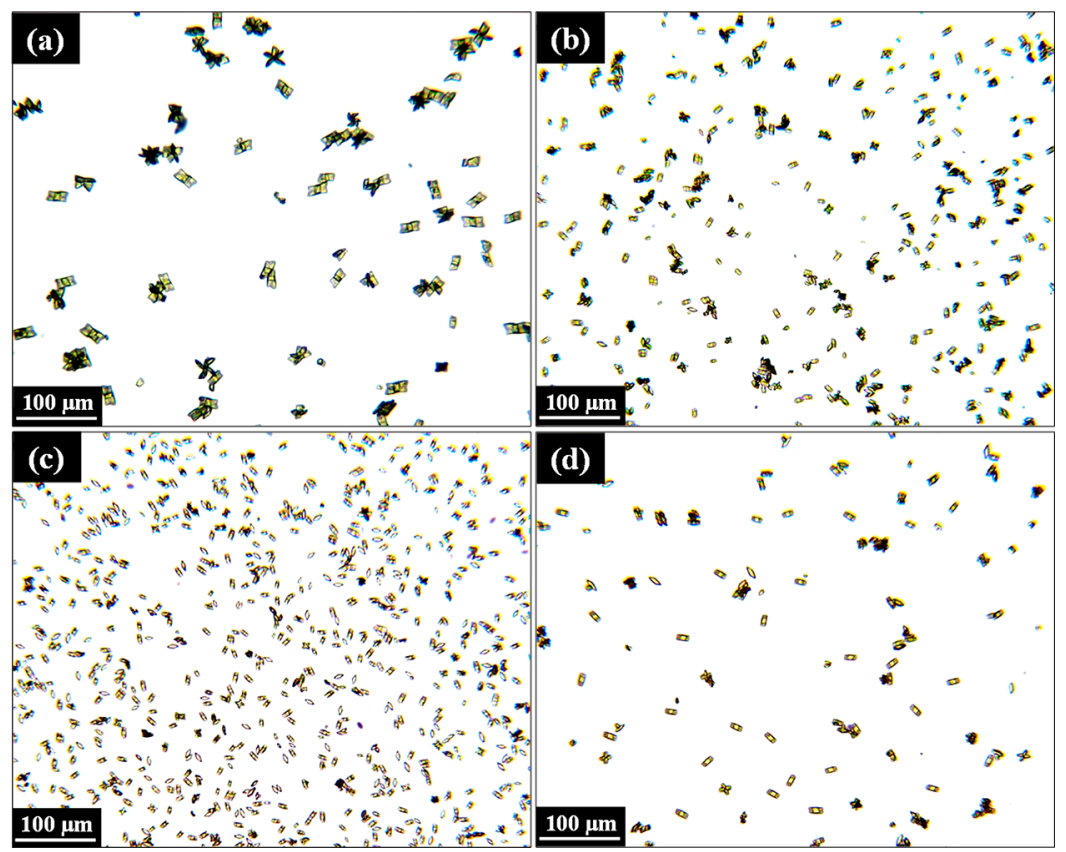

Figure 5. Microscopic images of microcrystals produced at $V_{\text {aq }} / V_{\text {or }}$ of (a) 5; (b) 10; (c) 20; and (d) 30. The PRX content in the organic phase $=25 \mathrm{~g}$ $\mathrm{L}^{-1}$, the HPMC concentration in the aqueous phase $=0.06 \mathrm{wt} \%$, ringed SS membrane.

and hinder the approach of growth units equally on all surfaces. ${ }^{61}$

3.3. Effect of Antisolvent/Solvent Ratio. The effect of antisolvent/solvent ratio was investigated by injecting $3 \mathrm{~mL}$ of the feed solution containing $25 \mathrm{~g} \mathrm{~L}^{-1} \mathrm{PRX}$ into $15,30,45,60$, and $90 \mathrm{~mL}$ of $0.06 \%(\mathrm{w} / \mathrm{w})$ HPMC solution agitated at 1,500 rpm to achieve a $V_{\text {aq }} / V_{\text {or }}$ value of $5,10,15,20$, and 30 , respectively. As shown in Figures 5 and 6, $d[4,3]$ was reduced from 21.2 to $8.4 \mu \mathrm{m}$ when $V_{\mathrm{aq}} / V_{\text {or }}$ increased from 5 to 20 , and then showed an increase on a further increase in $V_{\mathrm{aq}} / V_{\text {or }}$ from 20 to 30 .

Fewer agglomerates were formed in more diluted suspensions (Figure $5 \mathrm{c}, \mathrm{d}$ ), because agglomerates can only form when small crystallites collide with each other and the collision frequency of crystallites is proportional to the square of their number density. Also, a greater volume of antisolvent led to

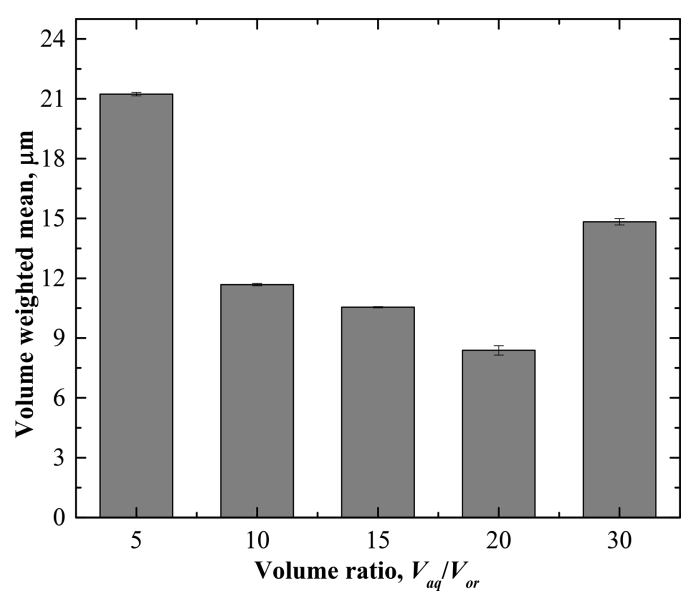

Figure 6. Average size of PRX monohydrate microcrystals as a function of volume ratio. The PRX content in the feed solution $=25 \mathrm{~g}$ $\mathrm{L}^{-1}$, the HPMC concentration in the aqueous phase $=0.06 \mathrm{wt} \%$, ringed SS membrane. higher solvent dilution after mixing; the final acetone concentration was $16.7 \mathrm{vol} \%$ at $V_{\mathrm{aq}} / V_{\text {or }}=5$ and only $4.8 \mathrm{vol}$ $\%$ at $V_{\text {aq }} / V_{\text {or }}=20$, which led to lower solubility, $C_{\mathrm{PRX}}{ }^{*}$, and higher supersaturation, $C_{\mathrm{PRX}}-C_{\mathrm{PRX}}{ }^{*}$, of $\mathrm{PRX}$ at $V_{\mathrm{aq}} / V_{\text {or }}=20$. During subsequent crystal growth, the higher antisolvent volume increases the diffusion path length of growth units, and diffusion may become the limiting step for the growth of nuclei. ${ }^{62,63}$ In addition, the critical nucleus size is smaller at higher supersaturation. ${ }^{64}$

A significant increase in $d[4,3]$ from 8.4 to $14.8 \mu \mathrm{m}$ was observed with a further increase in $V_{\mathrm{aq}} / V_{\text {or }}$ from 20 to 30 (Figure 6), probably due to suppressed secondary nucleation. Contact secondary nucleation is a significant additional source of small nuclei. ${ }^{65}$ Contact nucleation is triggered by contacts of existing parent crystals with the stirrer paddles, the vessel walls, and other crystals. Although the exact mechanism is still debatable, it is believed that contact nucleation originates from microattrition at the surface of a parent crystal or displacement of the semiordered clusters of solute molecules present at the mother liquor/crystal interface. ${ }^{66}$ Larger crystals at $V_{\text {aq }} / V_{\text {or }}=30$ were formed due to lower frequency of crystal-impeller and crystal-crystal contacts at higher dilution factor. Therefore, at low volume ratios $(5-10)$, nucleation kinetics was limited by thermodynamic factors (low supersaturation ratio), while at high volume ratios $(>20)$, the nucleation rate was limited by mechanistic factors (low collision frequency of crystals). Optical micrographs in Figure 5 are in good correlation with the results in Figure 6, showing that the crystal size decreases with a volume ratio up to $V_{\text {aq }} / V_{\text {or }}=20$ and then increases up to $V_{\text {aq }} / V_{\text {or }}=30$.

3.4. Effect of Membrane Cleaning Procedure. The role of the membrane cleaning was to ensure that the pores are not blocked by the deposited crystals and that the feed solution can penetrate uniformly into the aqueous phase. The membrane cleaning procedure was optimized in our previous study and verified by contact angle measurements. ${ }^{16}$ No difference in CSD was found in repeated experiments with clean membrane, 


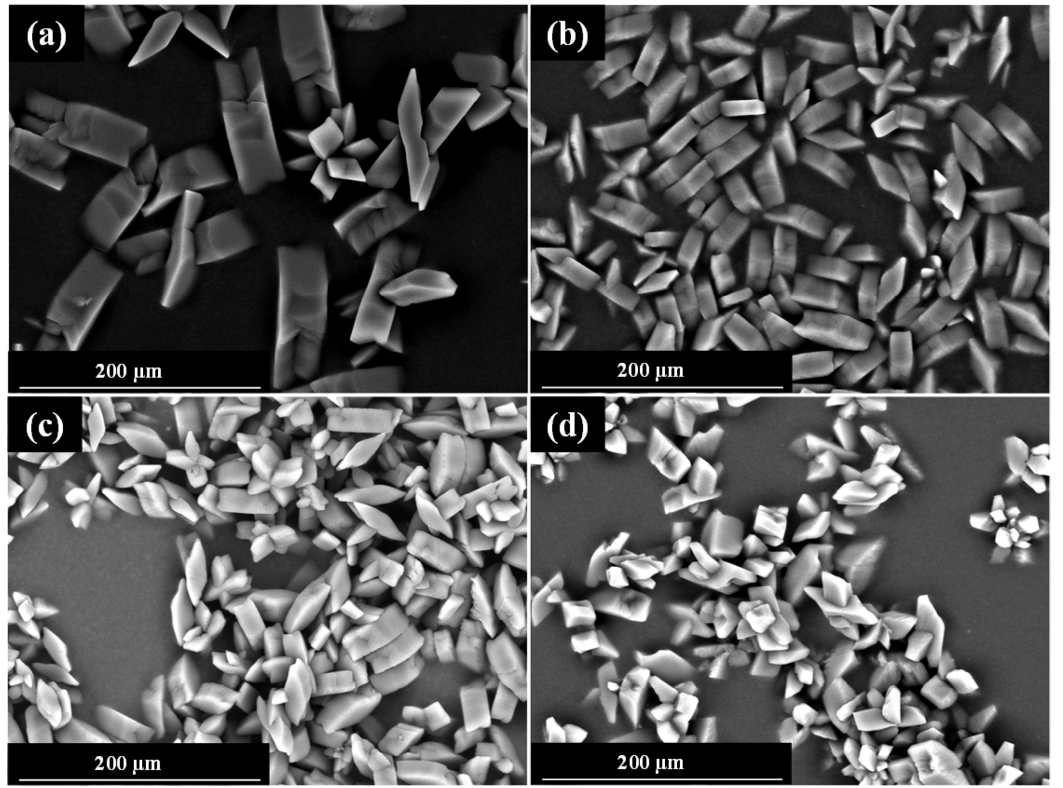

Figure 7. SEM images of PRX monohydrate microcrystals prepared using a ringed stainless-steel membrane with a pore size of $10 \mu \mathrm{m}$. Antisolvent was (a) Milli-Q water; (b) HPMC; (c) 0.06 wt \% P-123; and (d) 0.06 wt \% PVA. The PRX concentration in the feed solution was $25 \mathrm{~g} \mathrm{~L}^{-1}$.

as shown in Figure S2 (Supporting Information), which means that the cleaning procedure was appropriate. After cleaning, no clogged pores nor crystal deposits were observed on the membrane surface by a microscope.

3.5. SEM Analysis. Figure 7 shows SEM images of PRX monohydrate microcrystals prepared in pure water or in the presence of different surfactants dissolved at $0.06 \%(\mathrm{w} / \mathrm{w})$. The microcrystals in all samples exhibited an elongated rhombohedral shape. Because of high interfacial tension, the crystals formed in Milli-Q were clumped together into flower or starlike agglomerates (see Figure 7a). Because of steric hindrance induced by the adsorbed surfactant molecules, the crystals formed in the surfactant solutions were smaller and less aggregated (Figure $7 b-d$ ). The most uniform crystals with negligible agglomeration were formed in the presence of 0.06 wt \% HPMC. Because of their uniform size, these crystals had the highest tendency to stack together into densely packed parallel layers. More agglomerates were formed in the presence of P-123 and PVA, which is in good correlation with the optical micrographs shown in Figure 4, and confirm that HPMC is the best surfactant for stabilizing PRX monohydrate microcrystals in the antisolvent precipitation process.

3.6. Polymorphic form Validation. The Raman spectra of anhydrous PRX (Form I) and PRX monohydrate (Form II) obtained by membrane crystallization are shown in Figure 8a. The characteristic bands of polymorphic form I are at 1335 $\mathrm{cm}^{-1}$ due to symmetric $\mathrm{R}-\mathrm{NO}_{2}$ stretching, at $1523 \mathrm{~cm}^{-1}$ due to asymmetric $\mathrm{R}-\mathrm{NO}_{2}$ stretching, and in the region of $883 \mathrm{~cm}^{-1}$, corresponding to $\mathrm{C}-\mathrm{H}$ bonds in aromatic rings. On the other hand, PRX monohydrate showed characteristic peaks at 1007 and $1400 \mathrm{~cm}^{-1}$ regions related to $\mathrm{C}-\mathrm{H}$ stretching and symmetrical in-plane deformation of $\mathrm{CH}_{2}$, respectively. ${ }^{56,57}$ These spectra confirm a complete transformation of Form I to monohydrate achieved in the dispersion cell without using elevated temperature or supercritical conditions.

The DSC curves of anhydrous PRX (Form I) and PRX monohydrate (For II) prepared by membrane crystallization are shown in Figure $8 \mathrm{~b}$. A sharp endothermic peak of anhydrous PRX at $203{ }^{\circ} \mathrm{C}$ corresponds to its melting point.
Additional endothermic peak at $280{ }^{\circ} \mathrm{C}$ was due to the thermal degradation of pure PRX. The DSC curve of PRX monohydrate showed a broad endothermic peak at $150{ }^{\circ} \mathrm{C}$ corresponding to the loss of crystal water, which is consistent with previous studies. ${ }^{67,68}$ Dehydration usually begins at lattice defects or on the crystal surface, where the molecules are more energetic and then expands to the rest of the lattice with further increase in temperature. ${ }^{30}$ The second peak at $202{ }^{\circ} \mathrm{C}$ was due to the melting of the anhydrous form.

3.7. Comparison of Different Antisolvent Crystallization Systems. In this section, four different antisolvent crystallization methods were used to prepare PRX monohydrate microcrystals using pure water as antisolvent. Table 1 summarizes the operating conditions used and the average size and uniformity of the microcrystals obtained in each system.

Bulk mixing (method 1) is the simplest method of antisolvent crystallization. In this method, pure water was quickly poured into the feed solution without stirring or shaking, which resulted in large crystals $(d[4,3]=86 \pm 7.6 \mu \mathrm{m})$ and a very broad CSD $(\operatorname{span}=2.3)$ (Table 1 and Figure 9), due to uncontrollable mixing process. Furthermore, a mixture of prism-shaped (Form I) and needle-shaped (Form II) crystals was formed, as shown in the optical micrographs in Figure 10. The existence of two crystal shapes indicated that two different polymorphs were formed, due to poor mixing and generation of zones of different supersaturation levels. PRX precipitates in needle form (Form II) when allowed to crystallize from an ethanolic solution by fast cooling, while crystals in cubic form (Form I) are obtained by slow cooling from the same solution. ${ }^{69}$ In this case, the occurrence of needles can be explained by rapid addition of the antisolvent.

When the feed solution was directly injected into Milli-Q water stirred in the cell, without penetration through the membrane (Method 2), a bimodal CSD curve was obtained, as shown in the inset to Figure 9. The first peak at $\sim 30 \mu \mathrm{m}$ was from individual crystals, while the second shallow peak at $\sim 250$ $\mu \mathrm{m}$ originated from agglomerates, formed due to high local supersaturation levels near the feed injection point. The 

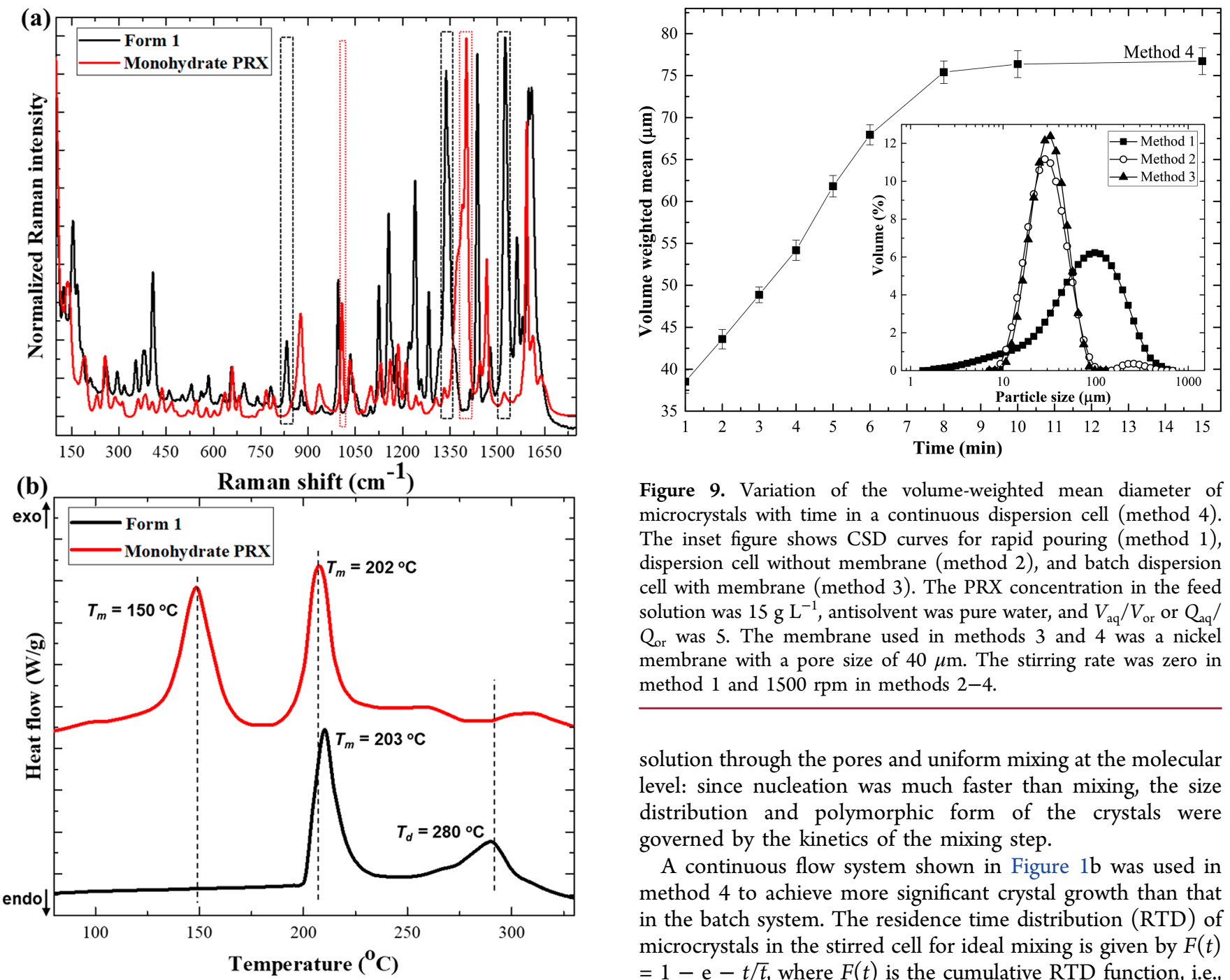

Figure 9. Variation of the volume-weighted mean diameter of microcrystals with time in a continuous dispersion cell (method 4). The inset figure shows CSD curves for rapid pouring (method 1), dispersion cell without membrane (method 2$)$, and batch dispersion cell with membrane (method 3). The PRX concentration in the feed solution was $15 \mathrm{~g} \mathrm{~L}^{-1}$, antisolvent was pure water, and $V_{\mathrm{aq}} / V_{\text {or }}$ or $Q_{\mathrm{aq}} /$ $Q_{o r}$ was 5 . The membrane used in methods 3 and 4 was a nickel membrane with a pore size of $40 \mu \mathrm{m}$. The stirring rate was zero in method 1 and $1500 \mathrm{rpm}$ in methods 2-4.

solution through the pores and uniform mixing at the molecular level: since nucleation was much faster than mixing, the size distribution and polymorphic form of the crystals were governed by the kinetics of the mixing step.

A continuous flow system shown in Figure $1 \mathrm{~b}$ was used in method 4 to achieve more significant crystal growth than that in the batch system. The residence time distribution (RTD) of microcrystals in the stirred cell for ideal mixing is given by $F(t)$ $=1-\mathrm{e}-t / t$, where $F(t)$ is the cumulative RTD function, i.e., the fraction of crystals exiting the cell that have spent a time $t$ or less in the cell and $\bar{t}$ is the mean residence time given by $V /\left(Q_{\mathrm{aq}}\right.$ $+Q_{\text {or }}$ ), where $V$ is the volume of the liquid in the cell. Since the residence time of crystals in the case of ideal mixing ranges from zero to infinity, some crystals will have much longer residence times than others. As a result, both tiny crystals and large aggregates can be found in the effluent stream after $1 \mathrm{~min}$ of operation (Figure 10). The average size of the microcrystals increased linearly from $38 \mu \mathrm{m}$ after $1 \mathrm{~min}$ to more than $75 \mu \mathrm{m}$ after $8 \mathrm{~min}$. The steady state was established after $8 \mathrm{~min}$ or $8.6 \bar{t}$, with only a minor further increase in mean crystal size between 8 and $15 \mathrm{~min}$. The results indicate that the continuous flow membrane crystallizer can be used to continuously produce

agglomerates of irregular shape are visible in the optical micrographs in Figure 10 (Method 2).

When the feed solution was injected through the membrane into stirred Milli-Q water (Method 3), a monomodal CSD curve was obtained (Figure 9) due to uniform supersaturation along the membrane surface. The microcrystals were more uniform and less aggregated than those prepared by direct injection (Figure 10), due to controlled addition of the feed

Table 1. Volume-Weighted Mean Diameter and the Span of PRX Microcrystals Prepared by Rapid Pouring (Method 1), Dispersion Cell without Membrane (Method 2), Batch Dispersion Cell with Membrane (Method 3), and Continuous Dispersion Cell (Method 4) ${ }^{a}$

\begin{tabular}{|c|c|c|c|c|c|c|}
\hline method & $V_{\mathrm{aq}} / V_{\text {or }}$ or $Q_{\mathrm{aq}} / Q_{\mathrm{or}}$ & stirring speed (rpm) & injection rate $\left(\mathrm{mL} \min ^{-1}\right)$ & flux $\left(\mathrm{L} \mathrm{m}^{-2} \mathrm{~h}^{-1}\right)$ & $d[4,3](\mu \mathrm{m})$ & $\operatorname{span}(-)$ \\
\hline 1 & 5 & & & & $86 \pm 7.6$ & $2.3 \pm 0.21$ \\
\hline 2 & 5 & 1500 & 18 & & $33 \pm 1.2$ & $1.3 \pm 0.06$ \\
\hline 3 & 5 & 1500 & 18 & 4000 & $29 \pm 0.7$ & $1.1 \pm 0.04$ \\
\hline $4^{b}$ & 5 & 1500 & 18 & 1300 & $39 \pm 1.4$ & $1.4 \pm 0.01$ \\
\hline
\end{tabular}

${ }^{a}$ The feed solution was $15 \mathrm{~g} \mathrm{~L}^{-1} \mathrm{PRX}$ in acetone injected at $18 \mathrm{~mL} \mathrm{~min}^{-1}$, and the antisolvent was pure water. A whole nickel membrane with a pore size of $40 \mu \mathrm{m}$ was used in Methods 3 and 4. Note: Each experiment was repeated at least three times. The error bars represent one standard deviation. ${ }^{b}$ Sample taken after $1 \mathrm{~min}$ of operation. 


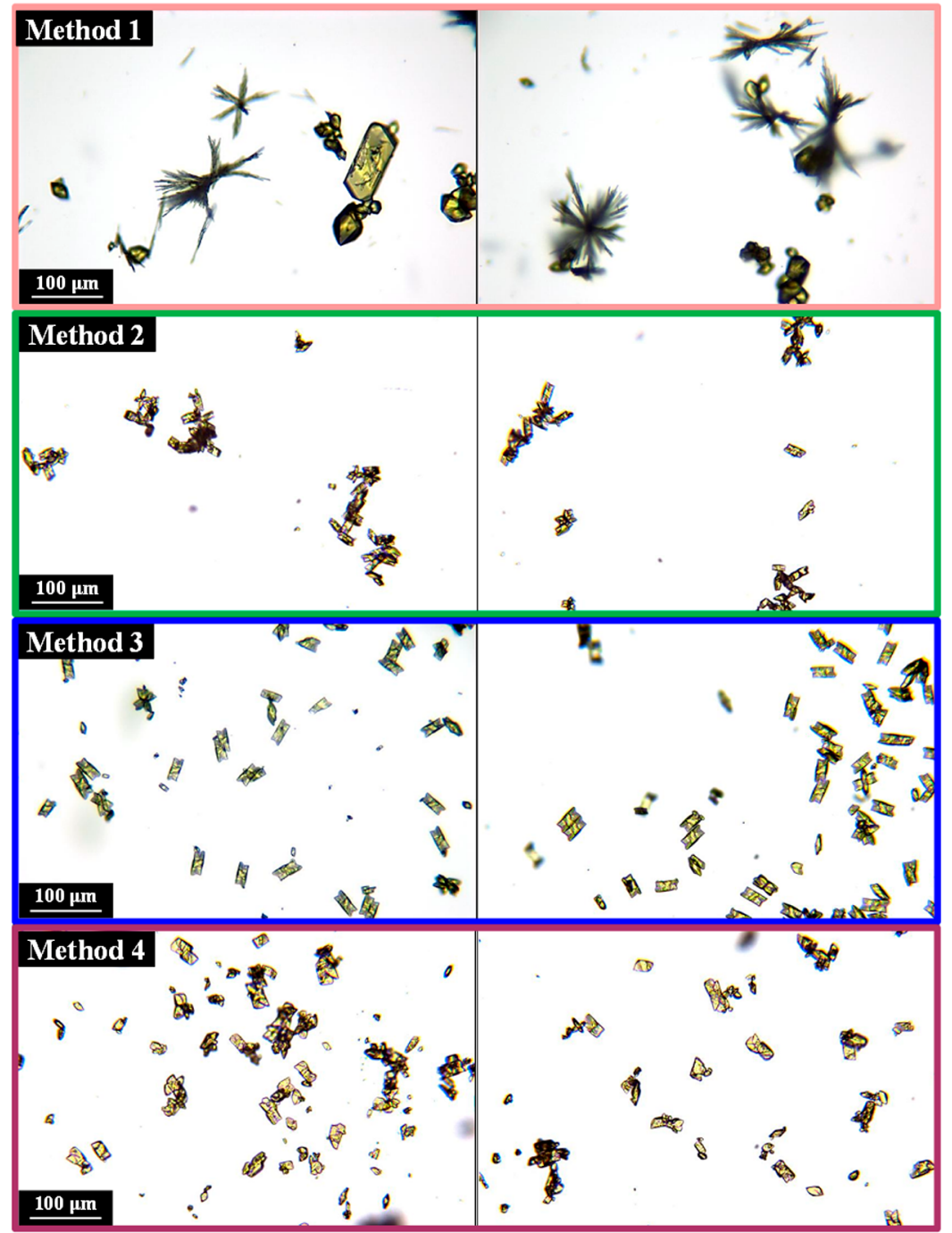

Figure 10. Optical micrographs of PRX monohydrate microcrystals prepared by different methods: (1) Rapid pouring; (2) dispersion cell without membrane; (3) batch dispersion cell with membrane; (4) continuous dispersion cell after $1 \mathrm{~min}$ of operation. Feed solution: $15 \mathrm{~g} \mathrm{~L} \mathrm{~L}^{-1} \mathrm{PRX}$ in acetone, $V_{\mathrm{aq}} / V_{\mathrm{or}}=5$ for methods $1-3$ and $Q_{\mathrm{aq}} / Q_{\mathrm{or}}=5$ for method 4. Membrane: $40-\mu \mathrm{m}$ Ni membrane in methods 3 and 4 . No surfactant was added.

relatively large crystals whose size can be controlled by the mean residence time. At constant flow rate of the organic phase through the membrane, the mean residence time in the cell can be reduced by increasing the flow rate of the aqueous phase, which would lead to a decrease in mean crystal size, and a steady state would be reached more quickly.

\section{CONCLUSIONS}

In this study, a novel membrane antisolvent crystallization technique has been developed and used for the preparation of piroxicam (PRX) monohydrate microcrystals. It was shown that PRX can precipitate in the cubic form by controlled addition of a piroxicam/acetone solution through the membrane pores into a well-stirred antisolvent. The size of PRX crystals was controlled by varying the concentration of PRX in the feed solution, antisolvent/solvent ratio, and the type and concentration of stabilizer in the aqueous phase. Higher supersaturations were achieved using the feed solution with a higher concentration of PRX, which promoted nucleation and led to smaller crystals. The crystals formed at an aqueous-to-organic volume ratio of 30 were larger than those obtained at the volume ratio between 10 and 20, due to inhibition of contact secondary nucleation. Rapid pouring of Milli-Q water into a $\mathrm{PRX} /$ acetone solution resulted in the precipitation of PRX in both cubic and needle forms, and the generated crystals were large and highly polydispersed, due to an uncontrolled mixing process.

Small drug crystals are desirable in the pharmaceutical industry to improve dissolution rate and bioavailability. The optimum procedure for producing small and nonaggregated PRX crystals with narrow size distribution was to inject a PRX/ acetone solution containing $25 \mathrm{~g} \mathrm{~L}^{-1}$ of PRX through a ringed stainless-steel membrane with a pore size of $10 \mu \mathrm{m}$ into an aqueous 0.06 wt $\% \mathrm{HPMC}$ solution at $1500 \mathrm{rpm}$ and $Q_{\mathrm{aq}} / Q_{\mathrm{or}}=$ 20. HPMC provided better steric stabilization of PRX crystals against agglomeration than PVA and P-123 surfactants, due to hydrogen bonding between HPMC and water or PRX molecules. A complete transformation of the anhydrous form of PRX into monohydrate was confirmed by Raman spectroscopy and DSC.

A continuous production of large PRX monohydrate crystals with a volume-weighted mean diameter above $75 \mu \mathrm{m}$ was 
achieved in a continuous dispersion cell. The size distribution of the formed crystals was broad, due to a wide range of residence times of crystal seeds in the crystallizer. More uniform crystal size distribution could be achieved using membrane crystallizers with more uniform residence time distribution, such as tubular cross-flow membrane modules, due to unidirectional flow of an antisolvent through the membrane tube.

\section{ASSOCIATED CONTENT}

\section{S Supporting Information}

This material is available free of charge via the Internet at http://pubs.acs.org/. The Supporting Information is available free of charge on the ACS Publications website at DOI: 10.1021/acs.cgd.7b01307.

Further explanations of the effect of organic solvent removal on the crystal size distribution and reproducibility of the method (PDF)

\section{AUTHOR INFORMATION}

\section{Corresponding Authors}

*(R.O.) E-mail: rahimah@unimap.edu.my.

*(G.T.V.) E-mail: G.Vladisavljevic@lboro.ac.uk.

ORCID

Goran T. Vladisavljević: 0000-0002-8894-975X

Elena Simone: 0000-0003-4000-2222

Zoltan K. Nagy: 0000-0003-4787-6678

Notes

The authors declare no competing financial interest.

\section{ACKNOWLEDGMENTS}

The authors acknowledge the financial support for this work received from the Ministry of Higher Education in Malaysia, the Engineering and Physical Sciences Research Council (Grant No. EP/HO29923/1), and the European Research Council (Grant No. 280106-CrySys). The assistance for SEM was provided by Shaun Fowler from the Department of Materials at Loughborough University.

\section{REFERENCES}

(1) Douroumis, D.; Fahr, A. Eur. J. Pharm. Sci. 2007, 30, 367-374.

(2) Merisko-Liversidge, E.; Liversidge, G. G.; Cooper, E. R. Eur. J. Pharm. Sci. 2003, 18, 113-120.

(3) Khadka, P.; Ro, J.; Kim, H.; Kim, I.; Kim, J. T.; Kim, H.; Cho, J. M.; Yun, G.; Lee, J. Asian J. Pharm. Sci. 2014, 9, 304-316.

(4) Löbenberg, R.; Amidon, G. L. Eur. J. Pharm. Biopharm. 2000, 50, $3-12$.

(5) Varshosaz, J.; Khajavinia, A.; Ghasemlu, M.; Ataei, E.; Golshiri, K.; Khayam, I. Dissolution Technol. 2013, 20, 15-23.

(6) Müller, R. H.; Jacobs, C.; Kayser, O. Adv. Drug Delivery Rev. 2001, 47, 3-19.

(7) Joshi, J. T. J. Pharm. Sci. Technol. 2011, 3, 651-681.

(8) Krause, K. P.; Müller, R. H. Int. J. Pharm. 2001, 214, 21-24.

(9) Kini, A. G.; Dixit, M.; Kulkarni, P. K. Int. J. Pharm. Pharm. Sci. 2011, 3, 231-235.

(10) Viçosa, A.; Letourneau, J. J.; Espitalier, F.; Inês Ré, M. J. J. Cryst. Growth 2012, 342, 80-87.

(11) Dong, Y.; Ng, W. K.; Shen, S.; Kim, S.; Tan, R. B. H. Int. J. Pharm. 2009, 375, 84-88.

(12) Zhang, J. Y.; Shen, Z. G.; Zhong, J.; Hu, T. T.; Chen, J. F.; Ma,

Z. Q.; Yun, J. Int. J. Pharm. 2006, 323, 153-160.

(13) Fessi, H.; Puisieux, F. Int. J. Pharm. 1989, 55, 1-4.
(14) Othman, R.; Vladisavljević, G. T.; Bandulasena, H. C. H.; Nagy, Z. K. Chem. Eng. J. 2015, 280, 316-329.

(15) Othman, R.; Vladisavljević, G. T.; Nagy, Z. K. Chem. Eng. Sci. 2015, 137, 119-130.

(16) Othman, R.; Vladisavljević, G. T.; Thomas, N. L.; Nagy, Z. K. Colloids Surf., B 2016, 141, 187-195.

(17) Othman, R.; Vladisavljević, G. T.; Shahmohamadi, H.; Nagy, Z. K.; Holdich, R. G. Chem. Eng. J. 2016, 304, 703-713.

(18) Rasenack, N.; Hartenhauer, H.; Müller, B. W. Int. J. Pharm. 2003, 254, 137-145.

(19) Zhao, H.; Wang, J. X.; Wang, Q. A.; Chen, J. F.; Yun, J. Ind. Eng. Chem. Res. 2007, 46, 8229-8235.

(20) Wang, Z.; Chen, J. F.; Le, Y.; Shen, Z. G.; Yun, J. Ind. Eng. Chem. Res. 2007, 46, 4839-4845.

(21) Meng, X.; Chen, Y.; Chowdhury, S. R; Yang, D.; Mitra, S. Colloids Surf., B 2009, 70, 7-14.

(22) Xie, S.; Poornachary, S. K.; Chow, P. S.; Tan, R. B. H. Cryst. Growth Des. 2010, 10, 3363-3371.

(23) Li, X. S.; Wang, J. X.; Shen, Z. G.; Zhang, P. Y.; Chen, J. F.; Yun, J. Int. J. Pharm. 2007, 342, 26-32.

(24) Zhang, H. X.; Wang, J. X.; Zhang, Z. B.; Le, Y.; Shen, Z. G.; Chen, J. F. Int. J. Pharm. 2009, 374, 106-113.

(25) Lindenberg, C.; Vicum, L.; Mazzotti, M.; Schöll, J.; Brozio, j. Cryst. Growth Des. 2008, 8, 224-237.

(26) Reis, N. M.; Liu, Z. K.; Reis, C. M.; Mackley, M. R. Cryst. Growth Des. 2014, 14, 3191-3198.

(27) Silva, R.; Ferreira, H.; Carvalho, A. C.; Gomes, A. C.; CavacoPaulo, A. Colloids Surf., B 2012, 92, 277-285.

(28) Javadzadeh, Y.; Siahi, M. R.; Asnaashari, S.; Nokhodchi, A. Pharm. Dev. Technol. 2007, 12, 337-343.

(29) Sheth, A. R.; Bates, S.; Muller, F. X.; Grant, D. J. W. Cryst. Growth Des. 2004, 4, 1091-1098.

(30) Sheth, A. R.; Zhou, D.; Muller, F. X.; Grant, D. J. W. J. Pharm. Sci. 2004, 93, 3013-3026.

(31) Charcosset, C.; Kieffer, R.; Mangin, D.; Puel, F. Ind. Eng. Chem. Res. 2010, 49, 5489-5495.

(32) Curcio, E.; Di Profio, G.; Drioli, E. J. J. Cryst. Growth 2003, 247, $166-176$

(33) Gugliuzza, A.; Aceto, M. C.; Drioli, E. Polym. Int. 2009, 58, $1452-1464$.

(34) Di Profio, G.; Stabile, C.; Caridi, A.; Curcio, E.; Drioli, E. J. Pharm. Sci. 2009, 98, 4902-4913.

(35) Drioli, E.; Di Profio, G.; Curcio, E. Curr. Opin. Chem. Eng. 2012, $1,178-182$.

(36) Bakker, W. J. W.; Geertman, R. M.; Reedijk, M. F.; Baltussen, J. J. M.; Bargeman, G.; Van Lare, C. E. J. Antisolvent solidification process, U.S. Patent 2013, 20130131029 A1.

(37) Laouini, A.; Jaafar-Maalej, C.; Sfar, S.; Charcosset, C.; Fessi, H. Int. J. Pharm. 2011, 415, 53-61.

(38) Holdich, R. G.; Dragosavac, M.; Vladisavljević, G. T.; Piacentini, E. Ind. Eng. Chem. Res. 2013, 52, 507-515.

(39) Holdich, R. G.; Dragosavac, M. M.; Vladisavljević, G. T.; Kosvintsev, S. R. Ind. Eng. Chem. Res. 2010, 49, 3810-3817.

(40) Vladisavljević, G. T.; Williams, R. A. J. Colloid Interface Sci. 2006, 299, 396-402.

(41) Laouini, A.; Charcosset, C.; Fessi, H.; Holdich, R. G.; Vladisavljević, G. T. RSC Adv. 2013, 3, 4985-4994.

(42) Laouini, A.; Koutroumanis, K. P.; Charcosset, C.; Georgiadou, S.; Fessi, H.; Holdich, R. G.; Vladisavljević, G. T. ACS Appl. Mater. Interfaces 2013, 5, 8939-8947.

(43) Othman, R.; Vladisavljević, G. T.; Nagy, Z. K.; Holdich, R. G. Langmuir 2016, 32, 10685-10693.

(44) User's Manual: Mastersizer 2000; Malvern Instruments Ltd.: United Kingdom, 2007.

(45) Davey, R.; Garside, J. From Molecules to Crystallizers. an Introduction to Crystallization; Oxford University Press Inc.: New York, 2000.

(46) Kurup, M.; Arun, R. R. Eur. J. Biomed. Pharm. Sci. 3, 2016, 230234. 
(47) Park, M. W.; Yeo, S. D. Sep. Sci. Technol. 2010, 45, 1402-1410.

(48) Cho, E.; Cho, W.; Cha, K. H.; Park, J.; Kim, M. S.; Kim, J. S.; Park, H. J.; Hwang, S. J. Int. J. Pharm. 2010, 396, 91-98.

(49) Simone, E.; Cenzato, M. V.; Nagy, Z. K. J. Cryst. Growth 2016, $446,50-59$.

(50) Simone, E.; Klapwjk, A. R.; Wilson, C.; Nagy, Z. K. Cryst. Growth Des. 2017, 17, 1695-1706.

(51) Klapwjk, A. R.; Simone, E.; Nagy, Z. K.; Wilson, C. Cryst. Growth Des. 2016, 16, 4349-4359.

(52) Canselier, J. P. J. Dispersion Sci. Technol. 1993, 14, 625-644.

(53) Shor, S. M. Effects of surfactants and inorganic additives on nucleation kinetics in mixed suspension crystallization, Ph.D. thesis, Iowa State University, 1970.

(54) Sardar, N.; Kamil, M.; Kabir-ud-Din. Ind. Eng. Chem. Res. 2012, $51,1227-1235$.

(55) Tsukada, Y.; Hara, K.; Bando, Y.; Huang, C. C.; Kousaka, Y.; Kawashima, Y.; Morishita, R; Tsujimoto, H. Int. J. Pharm. 2009, 370, 196-201.

(56) Hansen, T. B.; Qu, H. Cryst. Growth Des. 2015, 15, 4694-4700.

(57) Liu, G.; Hansen, T. B.; Qu, H.; Yang, M.; Pajander, J. P.; Rantanen, J.; Christensen, L. P. Chem. Eng. Technol. 2014, 37, 12971304.

(58) Tian, F.; Saville, D. J.; Gordon, K. C.; Strachan, C. J.; Zeitler, J. A.; Sandler, N.; Rades, T. J. Pharm. Pharmacol. 2007, 59, 193-201.

(59) Brunsteiner, M.; Jones, A. G.; Pratola, F.; Price, S. L.; Simons, S. J. R. Cryst. Growth Des. 2005, 5, 3-16.

(60) Nighute, A. B.; Bhise, S. B. Int. J. Pharm. Technol. Res. 2009, 1, 424-430.

(61) Garti, N.; Zour, H. J. Cryst. Growth 1997, 172, 486-498.

(62) Kakran, M.; Sahoo, N. G.; Tan, I. L.; Li, L. J. Nanopart. Res. 2012, 14, 3-11.

(63) Li, C.; Li, C.; Le, Y.; Chen, J. F. Int. J. Pharm. 2011, 404, 257263.

(64) Paulino, A. S.; Rauber, G.; Campos, C. E. M.; Maurício, M. H. P.; De Avillez, R. R.; Capobianco, G.; Cardoso, S. G.; Cuffini, S. L. Eur. J. Pharm. Sci. 2013, 49, 294-301.

(65) Wong, S. Y.; Cui, Y.; Myerson, A. S. Cryst. Growth Des. 2013, 13, 2514-2521.

(66) Cui, Y.; Myerson, A. S. Cryst. Growth Des. 2014, 14, 5152-5157.

(67) Lavrič, Z.; Pirnat, J.; Lužnik, J.; Seliger, J.; Zagar, V.; Trontelj, Z.; Srčič, S. J. Pharm. Sci. 2010, 99, 4857-4865.

(68) Vrečer, F.; Vrbinc, M.; Meden, A. Int. J. Pharm. 2003, 256, 315.

(69) Mihalić, M.; Hofman, H.; Kuftinec, J.; Krile, B.; Čaplar, V.; Kajfež, F.; Blažević, N. Anal. Profiles Drug Subst. 1986, 15, 509-531. 